Bangladesh J. Bot. 48(4): 1215-1221, 2019 (December)

\title{
EFFECTS OF WATER DEFICIT ON GROWTH AND PHYSIOLOGY OF YOUNG CONOCARPUS ERECTUS L. AND FICUS BENJAMINA L. SAPLINGS
}

\author{
Zikria Zafar*, Fahad Rasheed*, Muhammad Abdullah ${ }^{1}$, \\ Mir Md Abdus Salam ${ }^{2}$ and Muhammad Mohsin ${ }^{2}$ \\ Department of Forestry \& Range Management, University of Agriculture, \\ Faisalabad, Pakistan
}

Keywords: Water deficit, Biomass production, $\mathrm{CO}_{2}$ assimilation rate, Stomatal conductance, Water use efficiency

\begin{abstract}
A greenhouse experiment was conducted to investigate the effects of water deficit on growth and physiological parameters of Ficus benjamina and Conocarpus erectus. The results revealed that all growth parameters such as plant height, stem diameter, no. of leaves, no. of branches and chlorophyll contents significantly decreased under water deficit condition. Interestingly, although leaf, stem and total biomass production and allocation decreased significantly under water deficit, but root biomass production and allocation increased significantly. Similarly, stomatal conductance to water vapor decreased significantly and $\mathrm{CO}_{2}$ assimilation rate remained similar to control under water deficit condition. Resultantly, a significant increase in water use efficiency was evident in both species under water deficit condition. These results suggested that, in spite of a significant decrease in biomass production, young Conocarpus erectus and Ficus benjamina can tolerate water deficit which is due to sustained $\mathrm{CO}_{2}$ assimilation rate and increase in root biomass.
\end{abstract}

\section{Introduction}

The debate on climate change has evolved on to assess, mitigate and adapt to its impacts. This acceptance is based on evidence presented by the scientific community through intensive monitoring of changes in terrestrial systems and predictive modeling (IPCC 2013). Climate change does not merely imply increased average global temperature; other effects include lower frequency of heavy precipitation events and higher frequency of longer drought spells. Resultant scenario favors loss of biodiversity, redistribution and shrinkage of species ecological zones and decrease in productivity (Babst et al. 2013). In the last decade, regions around the globe have faced the negative impact of drought where United Nations Organization (UNO) reported that 2.18 billion hectors of lands were affected by water deficit in the world (Stuart et al. 2011). Globally, forest research has made immense progress in determining how drought affects species growth and productivity. Drought is one of the major abiotic factors to reduce the morphological, physiological and growth performances of plant (Lahlou and Ledent 2005). Morphological adaptation in different plant parts such as leaves, stems and roots are the potential indicators to assess the tolerance and adaption capacity of a species under water stress condition (Rasheed et al. 2015, Rasheed and Delagrange 2016). Drought reduces stomatal conductance and ultimately photosynthesis activities of a plant (Peguero-Pina et al. 2009). Therefore, it is crucial to make additional research on species in order to evaluate their adaptability under water stress to improve biomass production and ensure sustainable forestry. Pakistan has mostly arid and semiarid climates and about 7.8 million ha of land is facing drought stress, which has become a serious

*Author for correspondence: <z.zafarfrw@gmail.com, fahad.rasheed@uaf.edu.pk>. ${ }^{1}$ Cholistan Institute of Desert Studies, The Islamia University of Bahawalpur, Punjab, Pakistan. ${ }^{2}$ School of Forest Sciences, University of Eastern Finland, Joensuu, Finland, Pakistan. 
threat to forest productivity and cover (Aslam et al. 2002). The rapid decline of forest cover in Pakistan call for an urgent need of planting water stress tolerant species (Aslam et al. 2002). However, production sustainability of tree plantations will depend on the capacity of tree species to adapt to their future environment. Therefore, evidencing intraspecific phenotypic plasticity for morphological and physiological traits can be very useful in determining specie's capability to adapt to various abiotic stresses especially water deficit (Chaves et al. 2002). Conocarpus erectus L. (buttonwood) belongs to a family Combretaceae. It is an evergreen shrub/tree found in tropical and subtropical regions of the world (Hegazy et al. 2008), and is capable of growing on stony land, hammocks and salty areas. Ficus benjamina L. is native to India, China, Southeast Asia, Malaysia, the Philippines, south pacific and northern part of Australia (Riffle 1998). It is mostly found in urban area and is particularly used for ornamental purposes and to mitigate urban pollution (Dominí and Benítez 2004). Conocarpus erectus L. and Ficus benjamina L. were selected as target species to investigate the effects of water deficit on plants growth and physiology due to their good growth rates and tolerance capacity in the arid and semiarid climates. The main objective of this study was to evaluate the effects of water deficit on the growth, morphological and physiological parameters of Conocarpus erectus and Ficus benjamina.

\section{Materials and Methods}

The experiment was set up in a greenhouse at the Department of Forestry \& Range Management, University of Agriculture Faisalabad Pakistan ( $31^{\circ} 26^{\prime} \mathrm{N}, 73^{\circ} 06^{\prime} \mathrm{E}$ ) for a period of 90 days. The temperature in the greenhouse was maintained at $28^{\circ} \mathrm{C}$ with a photoperiod of $15 \mathrm{hrs}$, light at $28^{\circ} \mathrm{C}$ and dark period of $9 \mathrm{hrs}$ dark at $21^{\circ} \mathrm{C}$, and relative humidity at around $56 \%$. Threemonth-old healthy seedlings were collected from the nursery of Department of Forestry \& Range Management. Total 40 plants of Conocarpus erectus and Ficus benjamina seedlings (20 of Conocarpus erectus (10 pants control ,10 plants treatment); 20 of Ficus benjamina (10 pants control ,10 plants treatment) were planted into plastic pots $(34 \mathrm{~cm}$ diameter, $24 \mathrm{~cm}$ depth). Plastic pots were filled with peat sand mixture (2v/1v). Each pot was filled with $15 \mathrm{~kg}$ of dried soil. NPK fertilizer $\left(15 \% \mathrm{~N}, 5 \% \mathrm{P}_{2} \mathrm{O}_{5}, 5 \% \mathrm{~K}_{2} \mathrm{O}\right)$ was added at a rate of $5 \mathrm{~g} / \mathrm{kg}$ of soil to overcome nutrient deficiency. All the pots were rotated to avoid micro-climatic variations during the growth period. Pots under control condition were watered back to $80 \%$ of field capacity and pots under water deficit treatment were water back to $40 \%$ of the field capacity (Anjum et al. 2017). The stress treatment was regularly monitored by a moisture meter TRIME-EZ/-IT (IMKO Micromodultechnik GmbH, Germany). Plant height $(\mathrm{cm})$, stem diameter $(\mathrm{mm})$ at the collar, number of leaves and number of branches were measured manually from each individual throughout the experiment. Individuals in each treatment were harvested and divided into leaves, stem and roots and subsequently placed in the oven at $75^{\circ} \mathrm{C}$ for $72 \mathrm{hrs}$ till constant weight. The chlorophyll contents were measured on a fully mature and well-lit leaf produced during the stress treatment by using chlorophyll meter (FT GreenLlc Wilmington DE 19801 US.). One fully mature, well-lit leaf per individual per species was selected to measure gas exchange parameters using CIRAS-3 (PP- System, Amesbury, USA) and net $\mathrm{CO}_{2}$ assimilation rate $\left(A, \mu \mathrm{mol} \mathrm{m} \mathrm{m}^{-2} \mathrm{~s}^{-1}\right)$, stomatal conductance $\left(\mathrm{g}_{\mathrm{s}}, \mathrm{mol} \mathrm{m}^{-2} \mathrm{~s}^{-1}\right)$ and transpiration rate $\left(\mathrm{E}, \mathrm{mol} \mathrm{m}^{-2} \mathrm{~s}^{-1}\right)$ were measured under light intensity of $1200 \mu \mathrm{mol} \mathrm{m}^{-2} \mathrm{~s}^{-1}$ provided by red blue LEDs. Airflow through the cuvette was maintained at $500 \mathrm{ml} / \mathrm{min}$. Water use efficiency (WUE) was calculated as a ratio between $A$ and $\mathrm{g}_{\mathrm{s}}$. All the traits were analyzed using ANOVA for species, treatment and interaction effect. The significant differences between treatments were compared using Post-Hoc Tukey HSD test. All means were expressed along with their SE and all tests and correlations were taken significant at $\mathrm{p}$ $<0.05$. All statistical tests were performed in STATICTICA software, version 8.1, USA. 


\section{Results and Discussion}

Overall, species and interaction effects remained insignificant for almost all the traits related to growth, biomass production/allocation and leaf gas exchange parameters. Therefore, the result section mainly focusses on the treatment effect. Water deficit negatively affected almost all the growth parameters (plant height, stem diameter, no. of leaves, no. of branches) and chlorophyll contents of both tree species. The results showed that under water stress, minimum plant height and diameter was noted in Ficus species $(7.77 \mathrm{~cm}$ and $3.60 \mathrm{~mm}$, respectively; Fig. 1). The Conocarpus species performed better under water stress treatment showing a decrease of $47.4 \%$ in plant height, $36.6 \%$ in stem diameter, $61.5 \%$ in number of leaves and $9.64 \%$ in chlorophyll contents while Ficus showed a decrease of $60.7 \%$ in plant height, $34.9 \%$ in stem diameter, $55.9 \%$ in number of leaves, and $10.1 \%$ in chlorophyll contents. From the results it can be concluded that the Conocarpus species performed better under water stress and Ficus was found
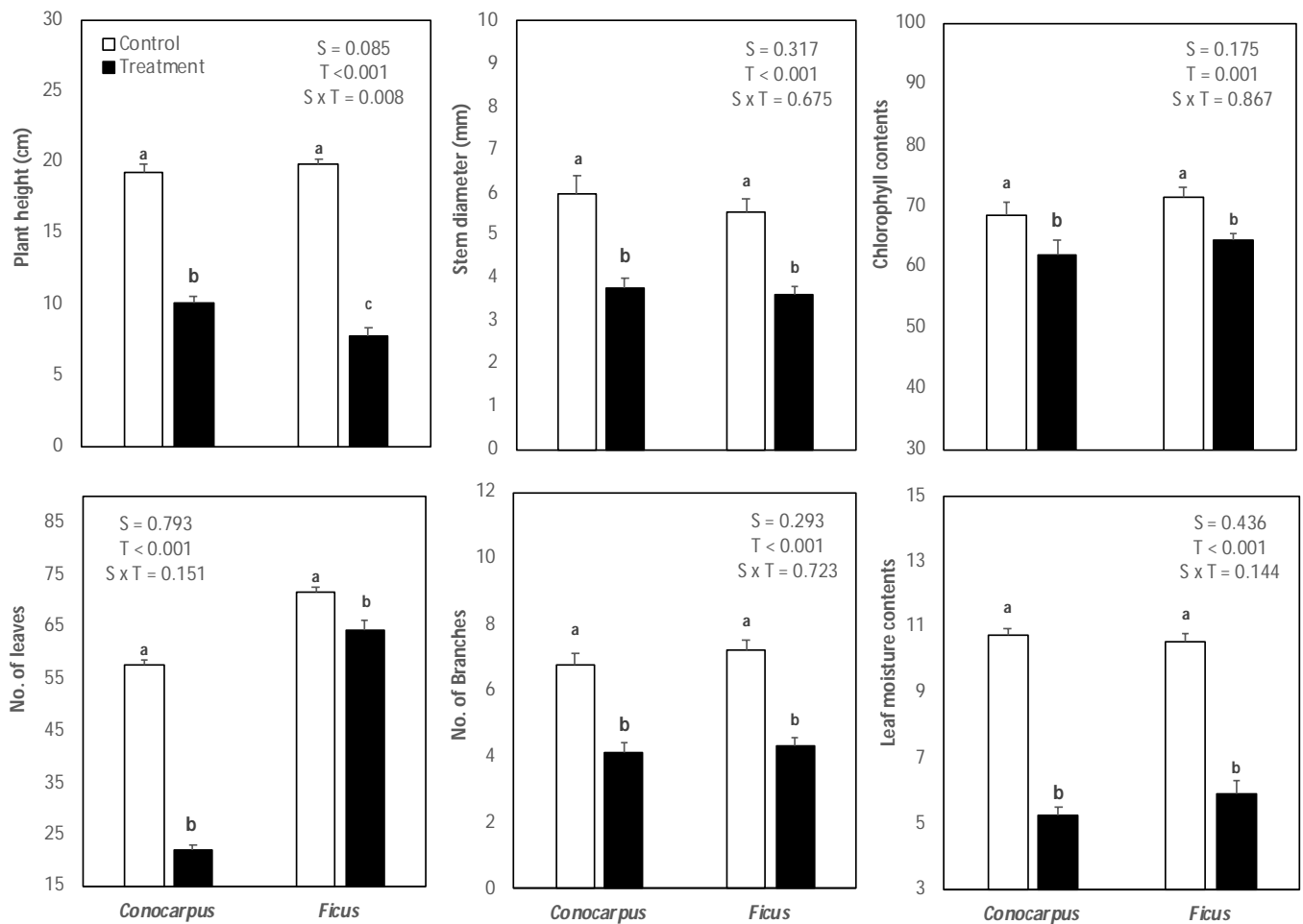

Fig 1. Growth parameters like plant height, stem diameter, chlorophyll contents, no. of leaves, no. of branches and leaf moisture contents were studied during the experiment. Data was analyzed using twoway ANOVA for species $(\mathrm{S})$, treatment $(\mathrm{T})$ and interaction $(\mathrm{S} \times \mathrm{T})$ effect and $\mathrm{P}$ values are given. Each bar represents means along with their SE. (Control 80 FC, treatment 40\% FC).

more sensitive to water stress. Under water stress, all the growth parameters decreased as compared to the control condition of both species. Our results were in consonance with the decrease in the stem height evidenced in S. lycopersicum species under moisture deficit (Aderolu 2000). Similarly, Kirnak et al. (2001) also reported similar findings where plant height and shoot length of the seedlings decreased under limited supply of water than in control condition. The 
reduction in plant height under limited supply of soil moisture have been observed due to decrease in turgor pressure, that influenced cell division and expansion subsequently biomass production depends upon both cell growth and development. Mwai (2002) described that cell growth and development is a procedure that depends upon three phases; cell division, enlargement and differentiation. Similar results where growth was decreased in drought-treated seedlings compared with the controls have been reported from previous study on 11 species including $Q$. robur and $Q$. pyrenaica Wild (Valladares and Sanchez-Gomez, 2006). In Populus trees, limited supply of water also resulted in inhibitory growth effects (Yin et al. 2005).

Leaf and stem biomass production as well as allocation decreased significantly under increasing water stress in both species, however root biomass production as well as allocation increased significantly in both species under water stress. The leaf biomass obtained for Conocrpus and Ficus decreased under well-water as compared to water stress where a slight decrease in Conocrpus $(13.9 \%)$ and a higher decrease in Ficus $(17.8 \%)$ was evidenced. However, stem dry weight of both species decreased in a similar fashion (Conocrpus $35.2 \%$ and Ficus 33.0 $\%)$. Interestingly root dry weight of both species were found insignificant different from each other under both conditions (Table 1). Root biomass of both species significantly increased under water stress treatment as compared with well water condition. Root biomass showed an increase of $20.0 \%$ in Concarpus and an increase of $11.3 \%$ in Ficus, respectively. Total biomass of Ficus seedlings was negatively influenced by drought stress, but Ficus species was less affected (a decrease of $21.7 \%$ in Conocarpus and a decrease of $18.7 \%$ in Ficus was evidenced). R : S ratio significantly increased under drought stress treatment in both species (Table 1). Root morphology determines the ability of the plant to explore soil and water resources. To sustain the uptakes and to reduce the water transpiration, seedlings in water stress environment normally reduces their plant height and leaf area, and increase the root length, leading to increase their root: shoot ratio (Yin et al. 2005). The increase of $\mathrm{R}: \mathrm{S}$ ratio is a common response under different stress types (Flexas et al. 2014). The previous reports have demonstrated that the tree adaptation under drought environment usually have larger $\mathrm{R}: \mathrm{S}$ ratio and longer roots system as compared to those which are not suitable under dry environmental condition (Hartmann 2011). So, trees adjusting to water stress tends to deepen their root system, thus sustaining water uptake, while at the same time less water loss from their leaves or other parts. Similar results have been evidenced in forest plants where they respond to drought by improving their root-to-shoot ratio and increasing root length (Poorter et al. 2012).

The gas exchange parameters of two species showed variation in their results. The ANOVA (Table 2) shows that significant treatment effect was evidenced in stomatal conductance however $\mathrm{CO}_{2}$ assimilation rate remained similar under water stress treatment. Resultantly, water use efficiency (WUE; the ratio between $\mathrm{CO}_{2}$ assimilation rate and stomatal conductance) increased significantly in response to drought stress. Furthermore, WUE increased by $51.1 \%$ in Conocarpus and $55.2 \%$ in Ficus species under water stress condition (Table 2). Similar results have been reported in previous studies where WUE was improved under drought environment (Liu et al. 2005; Rasheed et al. 2015). Reduction in photosynthesis is a usual plant response to water shortage that results in reduction in plant growth and development (Manes et al. 2006; Ghanbary et al. 2017). Under water deficit condition, the plants reduce stomatal conductance and under severe cases prevent the entry of $\mathrm{CO}_{2}$ into the leaves and has substantial influence on the growth condition, morphological structure and physiology and biochemistry of plants. Previous studies have pointed out that stomatal closure is one of the first responses to drought stress that causes a decline in the rate of photosynthesis (Flexas et al. 2014). In this study, the rate of photosynthesis and the stomatal conductance of both seedlings declined in response to drought stress. It is well known that the decrease in water potential and maintenance of water relations is one of the plant 

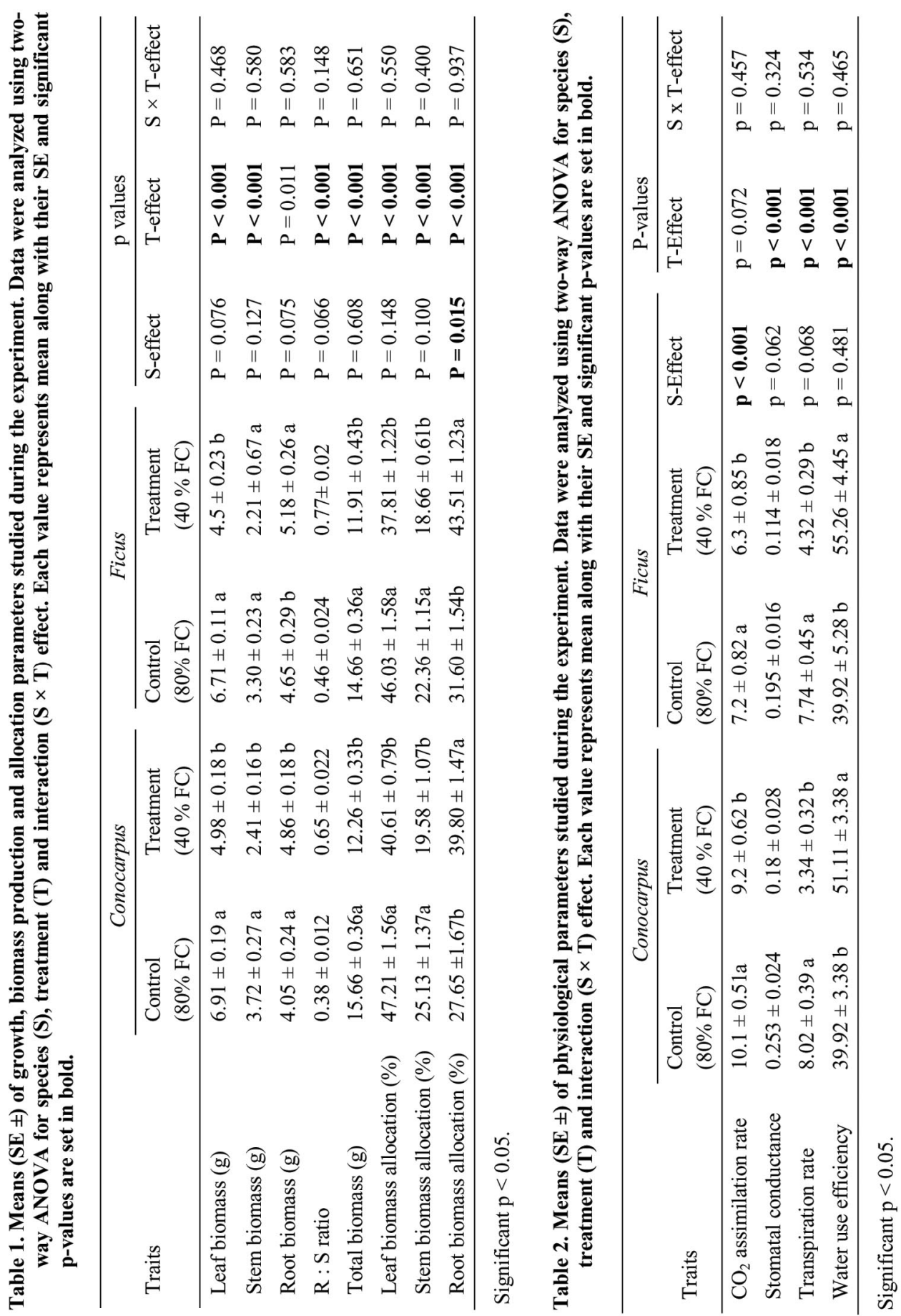
strategies in response to water limitation, which finally helps develop tolerance to drought stress. The higher WUE is a direct response to the reduction in stomatal conductance prior to the reduction in $\mathrm{CO}_{2}$ assimilation rate. This is a typical response observed in other plants when exposed to mild moisture deficit (El-Sharkawy 2007). However, others (Díaz-López et al. 2012) described synchronized decreased of stomatal conductance and net $\mathrm{CO}_{2}$ assimilation rate.

\section{Conclusion}

The results showed that both species respond in a similar way to water stress effect as species effect was found insignificant for almost all parameters. However, treatment effect was found significant where almost all parameters showed a decrease under water stress except for root biomass and $\mathrm{CO}_{2}$ assimilation rate. Resultantly root biomass allocation percentage also showed a significant increase in both species. Therefore, it is concluded that both species can tolerate water stress which is derived by sustained $\mathrm{CO}_{2}$ assimilation rate and a higher water use efficiency and biomass allocation to the roots that can help plants to survive under water stress conditions.

\section{Acknowledgements}

The authors are thankful to Dr. Hafiz Naeem Asghar, Institute of Soil \& Environmental Sciences for providing leaf gas exchange system and helping to take measurements. They also thankful to the anonymous reviewers for their suggestions to improve the manuscript.

\section{References}

Aderolu AM 2000. The effect of water stress at different growth stages on yield and seed quality of cowpea varieties. B. Agric Project, University of Ilorin, p. 68.

Anjum SA, Ashraf U, Tanveer M, Khan I, Hussain S, Shahzad B, Zohaib A, Abbas F, Saleem MF, Ali I and Wang LC 2017. Drought induced changes in growth, osmolyte accumulation and antioxidant metabolism of three maize hybrids. Front. Plant Sci. 8: 69.

Aslam M 2002. Salt affected soils options for rehabilitation. Pak. J. Soil. Sci. 21: 119.126.

Babst F, Poulter B and Trouet V 2013. Site and species-specific responses of forest growth to climate across the European continent. Glob. Ecol. Biogeogr. 22: 706-717.

Chaves MM, Pereira JS, Maroco JP, Rodrigues ML, Ricardo CPP, Osorio ML, Carvalh I, Faria T and Pinheiro C 2002. How plants cope with water stress in the field. Photosynthesis and growth. Ann. Bot 89: 907-916.

Díaz-López L, Gimeno V, Simón I, Martínez V, Rodríguez-Ortega WM and García-Sánchez F 2012. Jatropha curcas seedlings show a water conservation strategy under drought conditions based on decreasing leaf growth and stomatal conductance. Agric. Water. Manag. 105: 48-56.

Dominí ME and Benítez B 2004. Uso de biopreparados como promotores de enraizamientos en margullos de ficus (Ficus benjamina). Cultivos Tropicales 25 (3): 45-48.

El-Sharkawy MA 2007. Physiological characteristics of cassava tolerance to prolonged drought in the tropics implications for breeding cultivars adapted to seasonally dry and semiarid environments. Braz. J. Plant. Physiol 19: 257-286.

Flexas J, Diaz-Espejo A, Gago J, Galle A, Galmes J, Gulias J and Medrano H 2014. Photosynthetic limitations in Mediterranean plants: A review. Environ. Exper. Bot. 103: 12-23.

Ghanbary E, Tabari Kouchaksaraei M, Mirabolfathy M, Modarres Sanavi SAM and Rahaei M 2017. Growth and physiological responses of Quercus brantii seedlings inoculated with Biscogniauxia mediterranea and Obolarina persica under drought stress. For. Pathol 47(5).

Hartmann H 2011. Willa 385-million-year struggle for light become a struggle for water and for carbon? How trees may cope with more frequent climate change-type drought events. Global. Change. Biol. 17: 642-655. 
Hegazy SS, Aref IM, Al-Mefarrej H and El-Juhany LI 2008. Effect of spacing on the biomass production and allocation in Conocarpus erectus L. trees grown in Riyadh, Saudi Arabia. Saudi. J. Biol. Sci. 15: 315-322.

IPCC 2013. Climate Change 2013: The Physical Science Basis. Contribution of Working Group I to the Fifth Assessment Report of the Intergovernmental Panel on Climate Change. Cambridge University Press, Cambridge, United Kingdom and New York, NY, USA.

Kirnak H, Kaya C, Tas I and Higgs D 2001. The influence of water deficit on vegetative growth, physiology fruit yield and quality in eggplants. Bulg. J. Plant. Physiol. 27(3-4): 34-46.

Lahlou O and Ledent JF 2005. Root mass and depth stolon's and roots formed on stolon in four cultivars of potato under stress. Eur. J. Argon. 22:159-173.

Liu F, Andersen MN, Jacobsen SE and Jensen CR 2005. Stomatal control and water use efficiency of soybean (Glycine max L. Merr.) during progressive soil drying. Environ. Expt. Bot. 54: 33-40.

Manes F, Vitale M, Donato E, Giannini M and Puppi G 2006. Different ability of three Mediterranean oak species to tolerate progressive water stress. Photosynthetica 44: 387-393.

Mwai B 2002. Water deficits, cell division enlargement and shoot length on initial growth stages of groundnut (Arachis hypogea). Planta Med. 10: 92-98.

Peguero-Pina JJ, Sancho-Knapik D, Morales F, Flexas J, Gil-Pelegrin E 2009. Differential photosynthetic performance and photo-protection mechanisms of three Mediterranean evergreen oaks under severe drought stress. Funct. Plant. Biol. 36: 453-462.

Poorter H, Niklas K J, Reich PB, Oleksyn J, Poot P and Mommer L 2012. Biomass allocation to leaves, stems and roots meta-analyses of inter specific variation and environmental control. New Phytol. 193: 30-50.

Rasheed F and Delagrange S 2016. Acclimation of Betula alleghaniensis Britton to moderate soil water deficit: Small morphological changes make for important consequences in crown display. Tree Physiol. 36: $1320-1329$.

Rasheed F, Dreyer E, Richard B, Brignolas F, Brendel O and Le Thiec D 2015. Vapour pressure deficit during growth has little impact on genotypic differences of transpiration efficiency at leaf and wholeplant level: An example from Populus nigra L. Plant, Cell Environ. 38: 670-684.

Riffle RL 1998. The Tropical Look: An encyclopedia of dramatic landscape plants. Portland, Oregon: Timber Press.

Stuart ME, Gooddy DC, Bloomfield JP and Williams AT 2011. A review of the impact of climate change on future nitrate concentrations in groundwater of the UK. Sci. Total Environ. 409: 2859-2873.

Valladares F and Sanchez-Gomez D 2006. Ecophysiological traits associated with drought in Mediterranean tree seedlings: individual responses versus interspecific trends in eleven species. Plant. Biol. 8: 688-697.

Yin C, Wang X, Duan B, Luo J and Li C 2005. Early growth dry matter allocation and water use efficiency of two sympatric Populus species as affected by water stress. Environ. Exp. Bot. 53: 315-322. 